The inclusion of such subjects as "quantitative assessments of physical disablement,' ' employment, retirement and health' and 'the knowledge and use of social services ' indicate the fascinating social details included, while the chapters on 'cardiovascular disease,' ' high blood pressure,' and 'hearing, vertigo, tinnitus and vision' are most instructive.

In the final chapter the authors have summarized and commented upon their findings and introduced the subject of prevention of disease in a way and at a time most appropriate. This book is recommended to all those who are interested in the diseases of old age and in the social aspects of medicine.

\section{CARDIAC SYMPTOMS IN THE NEUROSES}

By Doris M. Baker, M.D., F.R.C.P. Pp. viii + 50, with 7 illustrations. London: H. K. Lewis \& Co., Ltd. 1955. 6s. 6d.

This short book deals briefly with the symptoms and signs of the condition variously known as effort syndrome, Da Costas syndrome, neurocirculatory asthenia and irritable heart. Sir Thomas Lewis preferred the first name ' which by refraining to imply the cause helps to maintain an attitude of enquiry toward the malady.' The author, however, considers it to be in disuse 'since the symptoms can occur quite independently of effort.' But what's in a name?

Left chest pain, sighing respiration and palpitation are examined in turn and the genesis of each symptom is discussed in the light of recent observations. Though nothing new is added to the body of knowledge about this common condition, the assembling of the facts is perhaps of value in once more insisting upon its existence as a clinical entity, upon recognition and the management of which the health and happiness of the patient may depend.

H.K.

\section{THE ROYAL SOCIETY OF MEDICINE: THE} REALIZATION OF AN IDEAL

By Maurice Davidson. Published by the Royal Society of Medicine. £I Is. od.

The Royal Society of Medicine, formerly the Medical and Chirurgical Society of London, was formed in 1805 when 26 members of the Medical Society of London seceded from that Society, after a resolution to limit the tenure of office of the president to three years had been defeated (at that time the president had held office continuously for r9 years). The resolution those 26 men passed when, at a later meeting, they met to form their new society, is of interest today; it was: "That a society comprehending the several branches of the medical profession be established in London for the purpose of conversation on professional subjects, for the reception of communications, and for the formation of a library and that this society be denominated "The Medical and Chirurgic Society of London ".'

In this fascinating book, Dr. Maurice Davidson. traces the history of the Royal Society of Medicines from its foundation, through its early struggles to its present mature state and then in a final chaptef he discusses the future which may lie in store for this great medical society. Dr. Davidson show how the society has lived up to the original ideas $\overline{\text { Af }}$ its founders, as stated in their first resolution; pef haps they did not envisage quite so impressive $-a$ result.

This book is recommended not only because it $\overrightarrow{i s}$ a pleasure to read and an interesting history of $\mathrm{g}^{\mathrm{g}}$ medical society, but because it contains more tham the bare facts of history.

\section{DIAGNOSIS AND TREATMENT OF THE ACUTE PHASE OF POLIOMYELITIS AND ITS COMPLICATIONS}

Edited by Albert G. Bower, M.D. Pp. $x+25 \overrightarrow{2}$ with 64 illustrations. London: Baillière, Tindafl and Cox, Ltd. I 955 . 50s.

This book on the diagnosis and treatment of agute poliomyelitis must command respect, for 通 largely written by the staff of the Los Angelles County Hospital, where great interest has taken in this subject in recent years. Like most books written by many contributors there is comsiderable repetition, but this may be excused singe the lessons of the book are important and not yot well enough known. Stress is laid on the importanee of recognizing respiratory failure before it $\mathrm{bE}-$ comes severe-if cyanosis develops the diagnosis has been missed-and of getting the patient who is in danger of respiratory paralysis to a place where team of doctors and nurses with adequate perience can care for him. The value of trachegtomy in cases with paralysis of swallowing is ex:phasized and the folly of allowing a patient to inhale vomit or secretions before doing a trachegtomy is demonstrated.

One major criticism must, however, be made. These workers do not ventilate their patients long periods with intermittent positive pressuse except in conjunction with a tank respirator. Thege is ample evidence from European experience tha intermittent positive pressure respiration throughora tracheotomy is both safe and convenient. It offers many advantages, notably free access to the patieg, and for the case with respiratory paralysis aftd difficulty in swallowing it will, in the reviewe's opinion, become orthodox treatment.

$\stackrel{\circ}{\circ}$ This book can be read with profit by all physicias s hospitals and wherever patients are admitted who require prolonged artificial respiration.

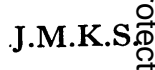

